Table 1. Comparison between the studied groups according to disease activity

\begin{tabular}{lcccc}
\hline & $\begin{array}{c}\text { Group I } \\
\mathbf{( 3 7 )}\end{array}$ & $\begin{array}{c}\text { Group II } \\
\mathbf{( 2 3 )}\end{array}$ & $\begin{array}{c}\text { Test of } \\
\text { Significance }\end{array}$ & P \\
\hline & Mean \pm SD & & $\mathbf{~ t ~}$ & \\
\hline CPDAI & $\begin{array}{l}8.68 \pm 3.33 \\
\text { Median (Minimum }\end{array}$ & $11.26 \pm 2.03$ & $3.735^{*}$ & $<0.001^{*}$ \\
& - Maximum) & & $\mathrm{U}^{*}$ & \\
PASI & $8.3(0-45.7)$ & $14.4(0.9-49.6)$ & $292.5^{*}$ & $0.043^{*}$ \\
DAPSA & $29(14-89)$ & $45.5(20.5-99)$ & $226.0^{*}$ & $0.002^{*}$ \\
C-reactive protein (mg/dl) & $6.3(0.3-72)$ & $6(0.8-61.6)$ & 409.5 & 0.802 \\
68 Tender joint count & $7(2-64)$ & $23(8-68)$ & $112^{*}$ & $<0.001^{*}$ \\
66 Swollen joint count & $2(0-23)$ & $4(0-10)$ & 300.5 & 0.055 \\
Leeds enthesitis index & $2(0-6)$ & $6(3-6)$ & $76.5^{*}$ & $<0.001^{*}$ \\
Dactylitic count & $0(0-8)$ & $0(0-7)$ & 421 & 0.924 \\
\hline
\end{tabular}

U: Mann Whitney test

t: Student t-test

$p: p$ value for comparing between the studied categories

*: Statistically significant at $p \leq 0.05$

Patients in both groups had similar functional level by health assessment questionnaire $(H A Q)(U=339, p=0.188)$ and $Q O L$ by PsAQOL $(U=306, p=0.068)$. While, MAF was statistically higher in group II patients 34 ranging from 28 to 48.7 in group II vs 26.5 ranging from 0 to 49.5 in group I $(U=172.5, p<0.001)$. In group II patients: the mean tender point count was $16.50 \pm 1.84$, fibromyalgia severity scale (FSS) was $20.7 \pm 3.99$ and fibromyalgia impact questionnaire (FIQ) was $57.22 \pm 7.30$. There was a statistically significant correlation between FSS and DAPSA $\left(r_{s}=0.59, p=0.003\right)$, PsAQOL $\left(r_{s}=0.64, p=0.001\right)$ and HAQ $\left(r_{s=} 0.613\right.$, $p=0.002)$, and between FIQ and PASI $(r=0.488, p=0.018)$, PsAQOL $(r=0.576$, $p=0.004), H A Q(r=0.557, p=0.006)$ and MAF $(r=0.619, p=0.002)$.

Conclusion: These results might highlight the importance of considering FM as a contextual factor in disease activity assessment in patients with PsA, especially in those with discrepancies in TJC/patients reported outcomes versus SJC/ inflammatory markers or persistently high disease activity indices.

References:

[1] Turkiewicz AM, Moreland LW. Psoriatic arthritis: Current concepts on pathogenesis-oriented therapeutic options. Arthritis Rheum 2007;56(4):1051-66. 2. Husted JA, Thavaneswaran A, Chandran V, Gladman DD. Incremental Effects of Comorbidity on Quality of Life in Patients with Psoriatic Arthritis. J Rheumatol 2013;40(8):1349-56. 3. Brikman S, Furer V, Wollman J, Borok S, Matz $\mathrm{H}$, Polachek A, et al. The effect of the presence of fibromyalgia on common clinical disease activity indices in patients with psoriatic arthritis: a cross-sectional study. J Rheumatol 2016;43(9):1749-54.

Acknowledgments: Our sincere gratification to our mentor the late Prof. Dr. Abdel Moneim Helal.

Disclosure of Interests: None declared

DOI: 10.1136/annrheumdis-2020-eular.1509

\section{AB0732 1 FATIGUE ASSESSMENT IN EGYPTIAN PSORIATIC ARTHRITIS PATIENTS: RELATION TO SERUM INTERLEUKIN 23, DISEASE ACTIVITY AND QUALITY OF LIFE.}

N. Aboeladl ${ }^{1}$, N. Elsawy ${ }^{2}$, M. Helal ${ }^{2}$, M. Elshafei ${ }^{3}$, N. Lewis ${ }^{4} .{ }^{1}$ Faculty of $^{2}$ Medicine, Helwan University, Rheumatology and Rehabilitation, Cairo, Egypt; ${ }^{2}$ Faculty of Medicine, Alexandria University, Physical Medicine, Rheumatology and Rehabilitation, Alexandria, Egypt; ${ }^{3}$ Faculty of Medicine, Alexandria University, Radio-diagnosis, Alexandria, Egypt; ${ }^{4}$ Faculty of Medicine, Alexandria University, Clinical and Chemical Pathology, Alexandria, Egypt

Background: Fatigue is a prevalent and fundamental phenomenon in psoriatic arthritis (PsA) patients. It often interferes with physical and social functions and may lead to social withdrawal, long-standing sick leave, disability and loss of work productivity. Fatigue is a prevalent symptom in patients with chronic rheumatic diseases. Cytokines as interleukin IL-23/17 play a pivotal role in the pathogenesis of PsA.

Objectives: To assess fatigue in PsA patients and determine its relation to serum IL 23 levels, disease activity, Skin severity, physical function and quality of life (QoL).

Methods: Fifty PsA patients and 46 matched healthy controls were included in this study. Skin severity based on the Psoriasis Area and Severity Index (PASI), the Disease Activity index for Psoriatic Arthritis (DAPSA) and the Functional Assessment of Chronic Illness Therapy (FACIT-F) were assessed. Physical function was assessed by the Health Assessment Questionnaire Disability Index (HAQ-DI) and health-related QoL was assessed using the Short Form
Health Survey (SF-36), Psoriatic Arthritis QoL (PsAQoL) and the Dermatology Life Quality Index (DLQI). Serum IL-23 levels were measured in the studied groups.

Results: The study included $23(46 \%)$ females and 27 (54\%) males with a mean age of $42.78 \pm 12.33$ years. The mean serum IL-23 level was significantly higher in PsA patients $(50.89 \pm 13.86 \mathrm{pg} / \mathrm{ml})$ than in controls $(43.88 \pm 6.34 \mathrm{pg} / \mathrm{ml})$ $(p=0.006)$. The FACIT score ranged from $2-41$. Severe fatigue (score $<30)$ was reported in 27 (54\%) PsA patients. There were significant correlations between FACIT-F and (DAPSA, PASI, HAQ-DI, PsAQoL, DLQI and SF-36). No significant correlations could be detected between FACIT-F and serum levels of IL-23 and CRP.

Conclusion: Fatigue was a frequent complaint in PsA patients. There was a mutual negative impact between fatigue and each of PsA joint disease activity and physical function and it worsened the QoL. Fatigue was worsened with increased severity of skin PsO. Although serum level of IL-23 was significantly elevated in PsA patients than the controls, it wasn't correlated with fatigue score. Hence IL-23 can't be considered a biomarker for fatigue severity.

References:

[1] Chandran V, Bhella S, Schentag C, Gladman DD. Functional Assessment of Chronic Illness Therapy-Fatigue Scale is valid in patients with psoriatic arthritis. Ann Rheum Dis 2007; 66(7):936.

[2] Mortada M, Abdul-Sattar A, Gossec L. Fatigue in Egyptian patients with rheumatic diseases: a qualitative study. Health Qual Life Outcomes 2015; 13:134

[3] Krajewska-Wlodarczyk M, Owczarczyk-Saczonek A, Placek W. Fatigue - an underestimated symptom in psoriatic arthritis. Reumatologia 2017; $55(3): 125-30$

[4] Strand V, Mease P, Gossec L, Elkayam O, van den Bosch F, Zuazo J, et al. Secukinumab improves patient-reported outcomes in subjects with active psoriatic arthritis: results from a randomised phase III trial (FUTURE 1). Ann Rheum Dis 2017; 76(1):203-7.

[5] Reygaerts T, Mitrovic S, Fautrel B, Gossec L. Effect of biologics on fatigue in psoriatic arthritis: A systematic literature review with meta-analysis. Joint Bone Spine 2018; 85(4):405-10

Table. Correlation between FACIT-F score and different parameters in patients group

\begin{tabular}{lcc}
\hline & \multicolumn{2}{c}{ FACIT-F } \\
\cline { 2 - 3 } & $\mathbf{r}_{\mathbf{s}}$ & $\mathbf{p}$ \\
\hline DAPSA & $-0.365^{*}$ & $0.009^{*}$ \\
PASI & $-0.424^{*}$ & $0.002^{*}$ \\
HAQ-DI & $-0.464^{*}$ & $0.001^{*}$ \\
PSAQoL & $-0.633^{*}$ & $<0.001^{*}$ \\
DLQI & $-0.492^{*}$ & $<0.001^{*}$ \\
SF-36 & $0.600^{*}$ & $<0.001^{*}$ \\
CRP & -0.167 & 0.247 \\
Serum IL-23 levels & -0.183 & 0.204 \\
\hline
\end{tabular}

$r_{s}$ : Spearman coefficient, *: Statistically significant at $p \leq 0.05$

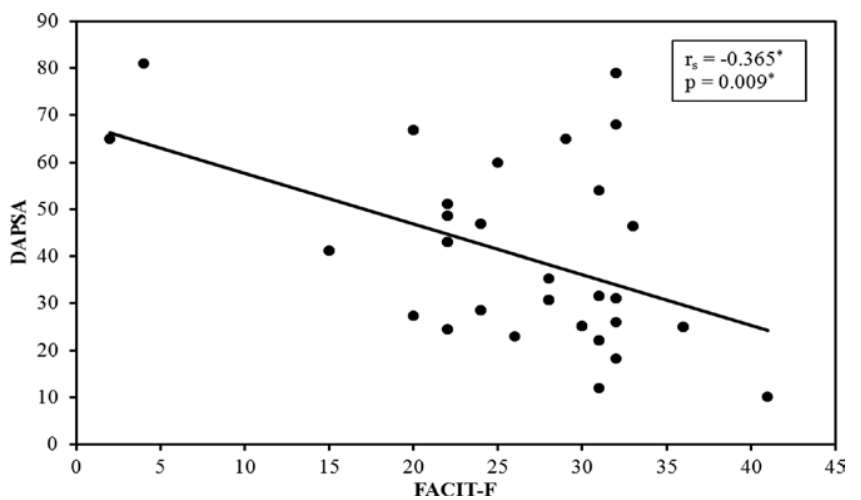

Figure. Correlation between FACIT-F and DAPSA in the studied PsA patients.

Acknowledgments: I am deeply indebted to my late Professor Abdelmoniem Helal for his expert guidance and keen interest throughout the work.

Thanks to My parents and Husband.

Disclosure of Interests: None declared

DOI: 10.1136/annrheumdis-2020-eular. 1560 